Article

\title{
The Effect of Enterprise Architecture Deployment Practices on Organizational Benefits: A Dynamic Capability Perspective
}

\author{
Rogier van de Wetering ${ }^{1, *}$, Sherah Kurnia ${ }^{2}$ and Svyatoslav Kotusev ${ }^{3}$ \\ 1 Department of Information Sciences, Open University of the Netherlands, 6419 AT Heerlen, The Netherlands \\ 2 Computing and Information Systems, Melbourne School of Engineering, The University of Melbourne, \\ Melbourne 3010, Australia; sherahk@unimelb.edu.au \\ 3 Higher School of Economics, National Research University, 101000 Moscow, Russia; kotusev@kotusev.com \\ * Correspondence: rogier.vandewetering@ou.nl; Tel.: +31-638-395-232
}

Received: 22 September 2020; Accepted: 20 October 2020; Published: 27 October 2020

check for updates

\begin{abstract}
In recent years, the literature has emphasized theory building in the context of Enterprise Architecture (EA) research. Specifically, scholars tend to focus on EA-based capabilities that organize and deploy organization-specific resources to align strategic objectives with the technology's particular use. Despite the growth in EA studies, substantial gaps remain in the literature. The most substantial gaps are that the conceptualization of EA-based capabilities still lacks a firm base in theory and that there is limited empirical evidence on how EA-based capabilities drive business transformation and deliver benefits to the firm. Therefore, this study focuses on EA-based capabilities, using the dynamic capabilities view as a theoretical foundation, and develops and tests a new research model that explains how dynamic enterprise architecture capabilities lead to organizational benefits. The research model's hypotheses are tested using a dataset that contains responses from 299 CIO's, IT managers, and lead architects. Based on this study's outcomes, we contend that dynamic enterprise architecture capabilities positively enhance firms' process innovation and business-IT alignment. These mediating forces are both positively associated with organizational benefits. The firms' EA resources and specifically EA deployment practices are essential in cultivating dynamic enterprise architecture capabilities. This study advances our understanding of how to efficaciously de-lineate dynamic enterprise architecture capabilities in delivering benefits to the organization.
\end{abstract}

Keywords: Enterprise Architecture (EA); enterprise architecture resources; deployment practices; dynamic enterprise architecture capabilities; dynamic capabilities; process innovation; business-IT alignment; organizational benefits

\section{Introduction}

Global technology trends like big data, the Internet of Things, and the rise of artificial intelligence are making firms' ability to change and adapt their organizations' structure, architecture, and people as crucial as their competitive strategy. These external forces and technology advances enact massive transformational changes within firms' business ecosystems, business units, and functions, and provide an opportunity to build capabilities in parallel with implementing a new strategic direction. Hence, firms need to accelerate the development of adaptive capabilities to ensure that the business can meet the needs of an increasingly complex environment. Moreover, firms need to embrace the business transformation journey to become top performers in the digital economy that are "future-ready" [1].

The increased frequency and speed of business-driven and information technology (IT)-driven change opportunities stress the importance of close alignment of IT resources, assets, and capabilities with business processes [2-4]. Enterprise Architecture (EA) can be considered a representation of a 
high-level view of enterprise business processes and the firms' IT systems, their interrelationships, and the extent to which different parts share these systems and processes within the enterprise [5]. EA is used within firms to provide firms with value across departments, processes, and business units to align strategic planning with business processes and state-of-the-art technology investments and deployment [2,3,5-8]. However, despite EA studies' richness over the past three decades, there is an inadequate understanding of the value created by EA and so-called EA-based capabilities that organize and deploy organization-specific resources to align strategic objectives with the particular use of technology $[4,5,9-11]$. Therefore, there is no conclusive evidence of how EA-based capabilities enable business transformations and deliver organizational benefits in constantly changing business environments [11-13].

This study aims to develop and test a new research model that explains how dynamic enterprise architecture capabilities lead to organizational benefits. Specifically, this study addresses how EA resources that focus on the development and deployment of EA artifacts enable EA-based capabilities conceptualized as dynamic capabilities. Addressing this question is essential, as these capabilities are considered cornerstones of EA deployment that drive decision-making processes, IT, and business capabilities $[2,4,14]$. This study follows the previous EA-based capability scholarship that used the dynamic capabilities view (DCV) $[2,4,15-19]$. The DCV provides a robust theoretical foundation and is accompanied by empirically-validated constructs and items $[2,4,20]$. Hence, this study contends that dynamic enterprise architecture capabilities, conceptualized as dynamic capabilities [20-22], allow firms to sense business and IT opportunities and threats [4,15].

Moreover, these capabilities allow firms to respond to these opportunities in the ever-changing economic environment $[4,23,24]$. The literature argues that the ability to cultivate the EA to reconfigure the business and the IT landscape successfully and adjust for, and respond to, unexpected changes is an essential driver for 'business-IT alignment' [25,26]. Previous studies also argue that dynamic enterprise architecture capabilities enable firms to gain access to previously unavailable EA resources and sets of decision options, which can ultimately enhance their ability to innovate using EA and contribute to organizational benefits $[27,28]$.

The extant literature proclaims that process innovation requires firms to (re)deploy IS/IT and other technologies to enhance the efficiency of new product development and commercialization [29]. Hence, this study aims to unfold the effect of dynamic enterprise architecture capabilities on organizational benefits. It is hypothesized that this particular effect is indirect and is mediated by other intermediate-capabilities and IT-business benefits, i.e., process innovation and business-IT alignment. Therefore, motivated by the call to provide evidence on how EA-based capabilities drive business transformation and deliver benefits, this study tries to answer three closely related research questions:

(1) What is the effect of enterprise architecture deployment practices on dynamic enterprise architecture capabilities?

(2) What is the effect of dynamic enterprise architecture capabilities on organizational benefits?

(3) Through what mechanisms do dynamic enterprise architecture capabilities lead to the achievement of organizational benefits?

This study proceeds as follows. First, this study outlines the theoretical ground and hypotheses development. Then, this work outlines the study design and methods. In the final sections, we present the key outcomes of this study and discuss the essential outcomes. This study ends with some concluding remarks.

\section{Theoretical Ground and Model Development}

This study builds upon the foundation of the resource-based view of the firm (RBV) and the DCV as its theoretical foundation. Specifically, the DCV is embraced as a theory to examine the proposed impact of dynamic enterprise architecture capabilities on organizational benefits. 


\subsection{Resources-Based Theories and EA Deployment Practices}

Much of the current IT-business value scholarship base their conceptualizations and arguments on the RBV $[30,31]$. The RBV is considered by many to be an influential theory in the IS that explains how firms can realize and maintain a competitive edge by using the firms' IT and business resources [30,32]. This particular theory seems to be a fitting 'lens' when investigating firms that try to leverage EA resources and capabilities to enhance operational capabilities, innovation, and competitive performance. The extant IS and management literature make a clear distinction between the process of deploying resources and capability-building. These are the two core elements of the RBV [31,33]. Amit and Schoemaker [34]) define a firm's resources as stocks of assets owned or controlled by the firms. On the contrary, capabilities are considered firm-specific capacity to deploy these particular resources, typically together with other organizational capabilities to achieve specific goals [32,34].

Syntheses from IS and management studies that use the RBV show that firms that use particular resources that can be considered valuable, rare, inimitable, and also non-substitutable (VRIN) ought to perform better in terms of competitive advantage. So, drawing from the RBV logic, this study argues that the specific deployment of a firms' EA resources and capabilities will result in the firm's operational and strategic benefits $[31,35,36]$. Hence, firms that do not actively invest in their (VRIN) EA resource portfolio may cause the deprivation of resources and the capabilities that build on these resources [37]. These insights are crucial for firms that want to excel with their EA practice to invest conscientiously. In that regard, the RBV acknowledges that the single investment in EA is not a sufficient condition for operational efficiencies and enhancing the firm's competitive nature. It can be deduced that it is thus more pertinent to identify the organizational capabilities that EA should be targeted in enabling or strengthening $[38,39]$. It seems that the literature requires a new theoretical perspective from which pathways to operational benefits can be systematically examined.

In recent years, the literature shows a wide variety of empirical work involving surveys, case research, and expert perspectives, demonstrating the reach and range of EA use in an organization's strategy implementation processes $[6,40]$. As such, the literature has emphasized deploying EA resources and assets so that they can be leveraged for business transformation [4,35]. EA resources primarily aim at developing and deploying EA artifacts. These particular artifacts can be considered unique documents that collectively describe various aspects of the entire EA within the organization [10, 41]. This study conceives EA resources as the EA deployment practices (or routines) that enable firms' capacity to benefit from EA's use. Hence, these EA resources are an essential antecedent of EA-based capabilities, i.e., capabilities that are enabled by EA's use, so that they can actively share assets and reconfigure and renew organizational resources [35].

\subsection{Dynamic Enterprise Architecture Capabilities}

The DCV extends the RBV and attempts to explain the processes through which a firm evolves in changing environments and maintains a competitive edge [42,43]. Due to conditions of high environmental uncertainty, market volatility, and frequent change, scholars have raised questions regarding the rate to which traditional operational and existing 'resource-based' capabilities erode and cease to provide competitive gains [27]. Dynamic capabilities are generally considered as the ability of organizations to integrate, reconfigure, gain, and release resources to match and even create market change [28,42].

In the context of strategic management and IS literature, recently, some researchers argue that EA-based capabilities are valuable to firms in the process of using, deployment, and diffusion of EA in decision-making processes and the organizational routines that drive IT and business capabilities [2,4,14]. Moreover, Shanks et al. [4] argue that EA-based capabilities are essential to leveraging EA advisory services. Likewise, Hazen et al. [2], following the DCV, provide foundational work that shows that EA-based capabilities can enhance organizational agility and indirectly enhance organizational performance. These outcomes are consistent with work by Foorthuis et al. [44] that demonstrates the importance of intermediate EA-enabled outcomes that contribute to the achievement 
of particular business goals and objectives. Hence, recent EA scholarship argues that complementary EA capabilities enable firms to leverage their EA effectively [2,5], contribute to IT efficiency and IT flexibility [45], and can drive alignment between business and IT [12].

This study concurs with this EA-based capability view. It considers dynamic enterprise architecture capabilities as a dynamic capability that helps organizations identify and implement new business and IT initiatives to ensure that the organizations' assets and resources are current with the business's needs. Following the tenets of the DCV, this study argues that it is likely that the extent to which EAs are leveraged successfully within the organization depends on the dynamic capabilities that collectively use the EA to sense environmental threats and business opportunities while simultaneously implementing new strategic directions. This study conceives dynamic enterprise architecture capabilities as the firm's ability to exploit its EA to share assets, and recompose and renew organizational resources under rapidly changing internal and external conditions to accomplish strategic objectives and the desired end state [20].

Starting from the conceptualization of dynamic capabilities by [42], and subsequently building on previous EA-based capability studies, this study synthesizes the reach and range of dynamic enterprise architecture capabilities through three related, but distinct, capabilities, i.e., EA sensing capability, EA mobilizing capability, and EA transformation capability. An EA sensing capability highlights EA's role in firms' deliberate posture toward sensing and identifying new business opportunities or potential threats and developing a greater reactive and proactive strength in the business domain $[4,15]$. An EA mobilizing capability refers to an organizations' capability to use EA in the process of evaluating, prioritizing, and selecting potential solutions and mobilizing firm resources in line with a potential solution $[4,23,24]$. Finally, an EA transforming capability can be considered the ability to use the EA to successfully reconfigure business processes and the technology landscape, to engage in resource recombination, and to adjust for and respond to unexpected changes $[4,27,36,46]$.

\section{Research Model and Hypotheses Development}

Figure 1 shows the proposed research model that contains four key constructs and the accompanying hypotheses. All the model's constructs and definitions are summarized in Table 1.

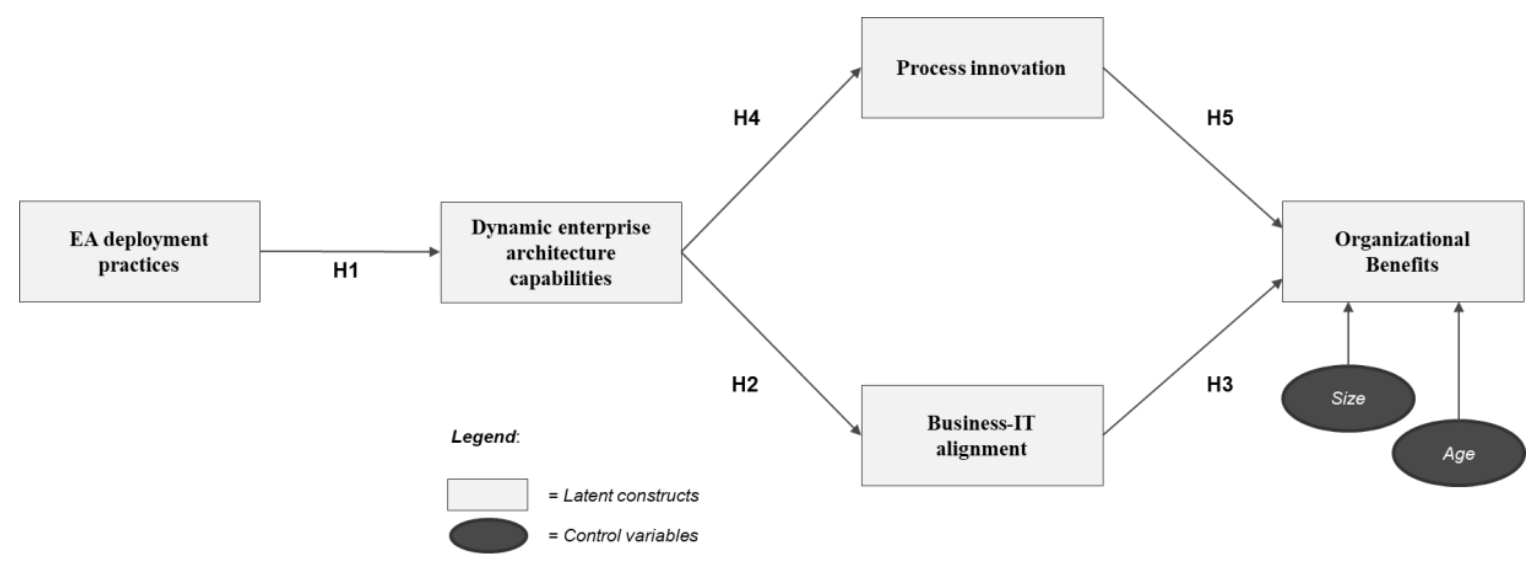

Figure 1. Research model. 
Table 1. Definitions of research constructs.

\begin{tabular}{ll}
\hline \multicolumn{1}{c}{ Construct } & \multicolumn{1}{c}{ Definition } \\
\hline Enterprise Architecture (EA) deployment practices & $\begin{array}{l}\text { EA practices (or routines) that deliberately use EA principles and } \\
\text { deployment approaches for the strategic usage of the firm IS/IT } \\
\text { (information technology) and business resources across the enterprise and } \\
\text { foster the development of context-relevant enterprise architectural } \\
\text { artifacts (e.g., models, business/IT mappings) across various architectural } \\
\text { layers (e.g., business, information, and infrastructure layer). }\end{array}$ \\
\hline Dynamic enterprise architecture capabilities & $\begin{array}{l}\text { A firm's ability to leverage its EA for asset sharing and to recompose and } \\
\text { renew organizational resources, together with guidance to proactively } \\
\text { address the rapidly changing internal and external business environment } \\
\text { and achieve the organization's desirable state. }\end{array}$ \\
\hline Process innovation & $\begin{array}{l}\text { The process view of the business with the application of innovation to the } \\
\text { firm's business processes. }\end{array}$ \\
\hline Business-IT alignment & $\begin{array}{l}\text { The extent to which the firms' business and IT plans, priorities, and } \\
\text { strategies are aligned. }\end{array}$ \\
\hline Organizational benefits & $\begin{array}{l}\text { The extent to which a firm has a higher competitive advantage than its } \\
\text { competitor(s), increased value for customers, and the ability to detect and } \\
\text { respond to opportunities and threats with ease, speed, and dexterity. }\end{array}$ \\
\hline [51,52] &
\end{tabular}




\subsection{EA Deployment Practices and Dynamic Enterprise Architecture Capabilities}

By building upon the RBV, it can be argued that competence in leveraging EA resources and deployment practices, by an EA-based capability, together with other complementary firm resources will likely result in competitive advantages [32,36]. Wade and Hulland [31] argued, however, that firms should actively invest in all the necessary resources so that they can cultivate potent EA resources. The literature contends that EA resources are an essential antecedent of EA-based capabilities and dynamic enterprise architecture capabilities $[4,22]$. The literature contends that leveraging effective EA deployment practices using EA methods and principles for the strategic usage of the firm's business and IS/IT resources $[47,48]$ will enable EA-based capabilities $[4,59,60]$. EA deployment practices use context-relevant EA artifacts (e.g., state and data diagrams, business process models, roadmaps, and frameworks) to represent the current (and future, to-be) business and IT across various architectural layers (e.g., business, information, and infrastructure layer) [50]. These artifacts can enhance the relationships and communication between various Business/IT stakeholders in the firm [10]. Using EA deployment practices, firms can facilitate processes to identify business problems and opportunities and various inefficiencies associated with current business processes and IT and prioritize the various improvement opportunities $[15,25]$. Given the above, it is likely that EA deployment practices will drive dynamic enterprise architecture capabilities. EA deployment practices are, thus, crucial in the process of achieving intermediate and also intangible EA-driven results and business value [22,61]. Hence, we expect that EA deployment practices will help develop dynamic enterprise architecture capabilities. Given the above, the current study proposes the first hypothesis:

\section{H1. EA deployment practices have a positive effect on the firm's dynamic enterprise architecture capabilities.}

\subsection{Dynamic Enterprise Architecture Capabilities and business-IT alignment}

Both in scientific literature and practice, it is a well-known fact that achieving a state of business-IT alignment (this research focuses on the measurement of alignment at a single point in time, rather than focusing on a process that evolves over time) is essential to leverage the maximum potential organizational benefits $[62,63]$. Business-IT alignment typically refers to the degree to which the IT strategies, objectives, and priorities appropriately and harmoniously support business strategies, objectives, and priorities [53,64,65]. As such, this research focuses on the antecedents and drivers of business-IT alignment and, hence, the content of alignment, i.e., the match between realized business and IT strategy [63]. This alignment dimension is classified in the literature as intellectual alignment' $[55,63,66]$.

Having a clear overview of the EA resources (e.g., EA content, EA standards, services, and other artifacts), and thus architectural transparency and a planned architectural design, can facilitate the process of integrating IT assets, resources, business processes, and services across various architectural layers $[44,67]$. EA can be leveraged to bridge the communication gap between business and IT stakeholders, facilitate cross-organizational dialogue and input [5], and improve business-IT-alignment [10,26]. Following the above discussion, it can be argued that dynamic enterprise architecture capabilities allow firms to continuously sense the on-going change within the organizations' internal and external business and IS/IT landscape and adequately respond by mobilizing firm resources to support business processes, specific user needs, and requirements using the EA [5]. Hence, this particular ability to cultivate the EA to successfully reconfigure the business and the IS/IT landscape, recombine resources, and adjust for and respond to unexpected changes is an essential driver for business-IT alignment. Hence, as firms proactively invest more in their dynamic enterprise architecture capabilities, one of the results is better business-IT-alignment [25,26]. Hence, the following is conjectured:

H2. Dynamic enterprise architecture capabilities have a positive effect on business-IT alignment. 


\subsection{Business-IT Alignment and Organizational Benefits}

Achieving a state of alignment comes with many organization benefit gains, including market growth, cost control, financial performance, increasing customer satisfaction levels, and augmented reputation $[53,55,63,65,66]$. Moreover, prior studies suggest that aligning the IT strategy with the business strategy will likely impact process agility and, thus, the way firms can easily and quickly reshape their business processes in turbulent business environments [55,68].

Although EA facilitates decision-making processes and brings the business and IT investment decisions in closer alignment to the organizational goals [5], EA by itself does not create any value for the firm [2,4]. Instead, IT and business managers can drive enterprise-wide transformational changes and provide the firm with various opportunities to build and deploy and capabilities while actively practicing its new strategic direction using the EA. Previous EA-based capabilities scholarship shows that many of EA's benefits are intangible, and value is achieved indirectly $[4,44]$. Therefore, this study theorizes that the business-IT alignment mediates the relation between dynamic enterprise architecture capabilities and organizational benefits. Thus, business-IT alignment is a crucial mediating force in the particular chain of EA value creation [38] and, therefore, a crucial antecedent of organizational benefits. Therefore, the following hypothesis is defined:

H3. Business-IT alignment mediates the relationship between dynamic enterprise architecture capabilities and organizational benefits.

\subsection{Dynamic Enterprise Architecture Capabilities and Process Innovation}

Given the unique nature of the dynamic enterprise architecture capabilities-in terms of their reach and range- and their hypothesized relationship with organizational benefits, it is likely that dynamic enterprise architecture capabilities have a positive impact not only on business-IT alignment, but also on the process innovativeness of the firm. Various scholars argue that process innovation is the outcome of organizational learning and EA resource orchestration for which the roots can be traced back to dynamic capabilities [69-71].

There are many other forms of innovation (e.g., business model, leadership) that relate mainly to process innovation [72]. This study focuses on process innovation (or 'process innovativeness'), as it has a central place in the extant literature, and this type of innovation requires firms to (re)deploy IS/IT and other technologies to enhance the efficiency of new product development and commercialization [29]. Teece et al. [73] concur with this view, as they note that strong dynamic capabilities are required for fostering the organizational agility and associated requirements necessary for innovation. It is crucial for firms to systematically re-allocate resources and improve service and production operation methods through technological advancements to drive process innovation [29].

EA-based sensing capabilities facilitate firms in their process to spot, interpret, and pursue new IS/IT and technological innovations (e.g., cloud, IoT, big data analytics, AI, business intelligence), business, and process opportunities or identify potential threats $[23,74]$. These capabilities help firms align their EA services with key stakeholders' demands, wishes, and needs, thereby positioning EA deployment practices so that targeted efforts for process innovation can be initiated. Moreover, EA-based capabilities foster organizational learning by designing both IT and business facets of the enterprise and its relationship with the business ecosystems to enable innovation and its ability to adapt in conjunction with the business environment $[25,75,76]$.

Once technological and business opportunities are first glimpsed, they must be addressed through maintaining and improving technological competences and complementary firm assets [21,36]. Hence, an EA-mobilizing capability allows firms to consciously direct investments in the firm's adaptiveness, use EA in the process of evaluating, prioritize and select potential IT and business solutions, and mobilize firm resources accordingly $[4,23,24,76]$. Thus, an EA-mobilizing capability is an essential ingredient for firms that want to adapt their resources and assets to the continually 
evolving customer wishes, demands and market, and technology trends, and shape their environment through innovation [21].

Finally, an EA transforming capability allows firms to engage in recombination and re-deployment of resources, change collaboration within the enterprise, and adjust for and respond to unexpected changes and the need for innovation $[4,27,36,77]$. Thus, dynamic enterprise architecture capabilities allow firms to use EA in decision-making processes and support competences to change the position of IS/IT and other firm resources through process innovation $[4,25,75,78]$. Hence, by these EA-based capabilities, firms can gain access to previously unavailable EA resources and sets of decision options, which can ultimately enhance their ability to innovate using EA and contribute to organizational benefits $[27,28]$. Hence, this study proposes the following hypothesis:

H4. Dynamic enterprise architecture capabilities have a positive effect on firms' level of process innovation.

\subsection{Process Innovation and Organizational Benefits}

The level of process innovation tends to not rely on individual resources. Instead, it seems that process innovation is based on unique combinations of complementary resources and the cooperation of cohesive units governed by EA-based capabilities $[5,9,45]$. The literature claims that EA-based capabilities are a precursor for process innovation. Process innovation enabled by dynamic enterprise architecture capabilities, in turn, influences organizational benefits in several ways, as previously documented in the literature $[29,51]$. Specifically, process innovation leads to better financial and operational results (e.g., return on investment, market growth, cost reduction) [79], enhanced levels of productivity, process efficiencies, and effectiveness [80], as well as enhanced levels of customers' perceived value [29]. Hence, the following hypothesis is defined:

H5. Process innovation will mediate the relationship between dynamic enterprise architecture capabilities and organizational benefits.

\section{Research Method and Design}

We selected a survey as the most appropriate method to test the research model and the proposed hypothesis. This study embraces a deductive approach that guides the study's design by focusing on predicting the key outcome construct in this study. Henceforth, claims are grounded in the existing body of knowledge, and this study also focuses on the development of persuasive arguments to substantiate these claims. As such, the current study required an extensive cross-sectional sample to test the model and the associated hypotheses.

\subsection{Data Collection and Sample Description}

A questionnaire was developed that included 38 main questions covering all relevant constructs in the research model (Table 2). Thirteen individuals pretested the survey, including IS scholars, enterprise architects, IT/business practitioners, and Master students, to enhance the survey items' content and face validity. The Netherlands belongs to the top European countries that deliver substantial economic impact using IT. Dutch firms are currently in a very proficient position to make use of the various economic and social opportunities created by digitalization, according to the Dutch Digitalization Strategy [81]. 
Table 2. Constructs and measurement items for EA deployment practices.

\begin{tabular}{|c|c|c|c|c|c|}
\hline \multicolumn{2}{|c|}{ Construct } & Measurement Item & \multirow[t]{2}{*}{$\lambda$} & \multirow[t]{2}{*}{$\mu$} & \multirow[t]{2}{*}{ Std. } \\
\hline \multicolumn{3}{|r|}{ Constructs and measurement items for EA deployment practices } & & & \\
\hline \multirow{4}{*}{$\begin{array}{l}\text { EA deployment } \\
\text { practices }\end{array}$} & \multicolumn{5}{|c|}{ Please choose the appropriate response for each item (1-strongly disagree, 7—strongly agree) } \\
\hline & DP1 & We use an EA framework approach or method for our EA development & 0.88 & 4.5 & 1.79 \\
\hline & DP2 & We use EA principles for the deployment and use of all IT assets and resources and organizational capabilities across the enterprise & 0.9 & 4.5 & 1.67 \\
\hline & DP3 & $\begin{array}{c}\text { Our EA outlines all the enterprise architectural artifacts (e.g., models, business/IT mappings) across various architectural layers (e.g., } \\
\text { business, information, and infrastructure layer) }\end{array}$ & 0.83 & 4.17 & 1.77 \\
\hline \multicolumn{6}{|c|}{ Constructs and measurement items for dynamic enterprise architecture capabilities } \\
\hline \multicolumn{6}{|c|}{ To what extent do you agree with the following statements (1-strongly disagree, 7-strongly agree)? Mobilizing and transforming capability use the same Likert Scale. } \\
\hline \multirow{5}{*}{$\begin{array}{l}\text { Sensing } \\
\text { capability }\end{array}$} & EAS1 & We use our EA to identify new business opportunities or potential threats & 0.77 & 3.83 & 1.61 \\
\hline & EAS2 & We review our EA services regularly to ensure that they are in line with key stakeholders wishes & 0.84 & 4.1 & 1.6 \\
\hline & EAS3 & We adequately evaluate the effect of changes in the baseline and target EA on the organization & 0.86 & 4.02 & 1.48 \\
\hline & EAS4 & We devote sufficient time to enhance our EA to improve business processes & 0.82 & 4.01 & 1.56 \\
\hline & EAS5 & We develop greater reactive and proactive strength in the business domain using our EA & 0.85 & 4.04 & 1.54 \\
\hline \multirow{5}{*}{$\begin{array}{l}\text { Mobilizing } \\
\text { capability }\end{array}$} & EAM1 & We use our EA to draft potential solutions when we sense business opportunities or potential threats & 0.85 & 4.39 & 1.51 \\
\hline & EAM2 & We use our EA to evaluate, prioritize, and select potential solutions when we sense business opportunities or potential threats & 0.86 & 4.37 & 1.51 \\
\hline & EAM3 & We use our EA to mobilize resources in line with a potential solution when we sense business opportunities or potential threats & 0.88 & 4.19 & 1.45 \\
\hline & EAM4 & We use our EA to draw up a detailed plan to carry out a potential solution when we sense business opportunities or potential threats & 0.87 & 4.12 & 1.59 \\
\hline & EAM5 & $\begin{array}{l}\text { We use our EA to review and update our practices in line with renowned business and IT best practices when we sense business } \\
\text { opportunities or potential threats }\end{array}$ & 0.84 & 4.22 & 1.48 \\
\hline \multirow{6}{*}{ Trans. capability } & EAT1 & $\begin{array}{l}\text { Our EA enables us to successfully reconfigure business processes and the technology landscape to come up with new or more } \\
\text { productive assets }\end{array}$ & 0.85 & 4.4 & 1.45 \\
\hline & EAT2 & $\begin{array}{l}\text { We successfully use our EA to adjust our business processes and the technology landscape in response to competitive strategic moves or } \\
\text { market opportunities }\end{array}$ & 0.87 & 4.17 & 1.56 \\
\hline & EAT3 & We successfully use our EA to engage in resource recombination to match our product-market areas and our assets better & 0.83 & 3.95 & 1.47 \\
\hline & EAT4 & Our EA enables flexible adaptation of human resources, processes, or the technology landscape that leads to competitive advantage & 0.84 & 3.88 & 1.5 \\
\hline & EAT5 & We successfully use our EA to create new or substantially changed ways of achieving our targets and objectives & 0.87 & 4.06 & 1.51 \\
\hline & EAT6 & Our EA facilitates us to adjust for and respond to unexpected changes & 0.8 & 4.02 & 1.46 \\
\hline
\end{tabular}


Table 2. Cont

\begin{tabular}{|c|c|c|c|c|c|}
\hline \multicolumn{2}{|c|}{ Construct } & Measurement Item & $\lambda$ & $\mu$ & Std. \\
\hline \multicolumn{6}{|c|}{ Constructs and measurement items for the mediating forces, i.e., business/IT-alignment, and process innovation } \\
\hline \multicolumn{6}{|c|}{ Please choose the appropriate response for each item (1-strongly disagree, 7-strongly agree) } \\
\hline \multirow{3}{*}{ Alignment } & BA1 & Our organization has a business plan to use existing technology to enter new market segments & 0.81 & 4.31 & 1.63 \\
\hline & BA2 & Our organization has a business plan to develop new technologies for new kinds of products/services & 0.81 & 4.61 & 1.61 \\
\hline & BA3 & Business and IT strategies are consistent & 0.81 & 4.41 & 1.52 \\
\hline \multirow{5}{*}{ Process inn. } & \multicolumn{5}{|c|}{$\begin{array}{c}\text { How would you rate your organization's process innovation capabilities in comparison to the main competitors in the same industry }(1=\text { much weaker than competition; } 7=\text { much stronge } \\
\text { than competition)? }\end{array}$} \\
\hline & PI1 & The technological competitiveness & 0.84 & 4.67 & 1.33 \\
\hline & PI2 & The updated-ness or novelty of technology used in key processes & 0.88 & 4.55 & 1.31 \\
\hline & PI3 & The speed of adoption of the latest technological innovations in key processes & 0.88 & 4.26 & 1.42 \\
\hline & PI4 & The rate of change in key processes, techniques, and technology & 0.88 & 4.19 & 1.36 \\
\hline \multicolumn{6}{|c|}{ Constructs and measurement items for organizational benefits } \\
\hline \multicolumn{6}{|c|}{ How would you rate your firm's process agility aspects in comparison to industry competitors (1. Much weaker than the competition-7. Much stronger than the competition)? } \\
\hline \multirow{13}{*}{$\begin{array}{l}\text { Organizational } \\
\text { benefits }\end{array}$} & PA1 & Expanding into new regional or international markets & 0.7 & 4.35 & 1.33 \\
\hline & PA2 & Responsiveness to customers & 0.81 & 4.71 & 1.22 \\
\hline & PA3 & Responsiveness to changes in market demand & 0.88 & 4.55 & 1.17 \\
\hline & PA4 & Customization of products or services to suit indiv. customers & 0.68 & 4.87 & 1.28 \\
\hline & PA5 & Adopt new technologies to produce better, faster, and cheaper products and services & 0.7 & 4.4 & 1.3 \\
\hline & \multicolumn{5}{|c|}{$\begin{array}{c}\text { Please choose the appropriate response for each item (1-strongly disagree, 7-strongly agree). During the last } 2 \text { or } 3 \text { years, we performed much better than our main competitors in the same } \\
\text { industry in: }\end{array}$} \\
\hline & CA1 & Growth in market share & 0.86 & 4.65 & 1.33 \\
\hline & CA2 & Profitability & 0.91 & 4.54 & 1.35 \\
\hline & CA3 & Sales growth & 0.91 & 4.54 & 1.33 \\
\hline & CA4 & Return on investment (ROI) & 0.84 & 4.41 & 1.29 \\
\hline & VL1 & Increasing customer satisfaction & 0.91 & 4.88 & 1.27 \\
\hline & VL2 & Increasing customer loyalty & 0.92 & 4.76 & 1.27 \\
\hline & VL3 & Enhancing business brand and image & 0.87 & 4.84 & 1.34 \\
\hline
\end{tabular}


Students of an advanced Business and IT Master course on Enterprise Architecture and organizational capabilities of a Dutch University were asked to participate in this survey. These particular Master students are experienced business or IT managers, consultants, and senior practitioners, and therefore, can represent the firm-wide view. They are most likely familiar with the strategic role of EA within the firm. They were voluntarily asked to fill in the survey from the organization's particular perspective where they currently work. Nonetheless, to ensure a collective and firm-wide view, the respondents were also invited to consult their managers (or any other colleague) if they were unsure about a particular survey item. Additionally, all students $(n=235)$ had to distribute this survey to two knowledgeable domain experts from other organizations (e.g., CIOs, IT managers, and lead enterprise architects) following a snowball method.

The survey was put to a rigorous pretesting procedure, enhancing both the reliability and validity. Additionally, construct definitions were provided to the respondents and the survey followed a logical structure. Respondents were offered a research report with the most important outcomes of this study. Anonymity was guaranteed, and respondents could withdraw their scores if they wanted to. The final survey was used to collect data as part of a field study. During the data collection, various controls were also built so that every organization completed the survey only once. The data collection phase started on the 17th of October 2018 and ended on the 16th of November 2018.

A total of 669 unique respondents from different organizations participated in the survey. After removing cases with either (partly) incomplete $(n=290)$ or unreliable values $(n=80)$, this study includes a total of 299 usable questionnaires for the analyses. The majority of respondents operate in the private sector (i.e., $57 \%$ ) and the public sector (i.e., $36 \%$ ). Only a small percentage (i.e., $7 \%$ ) comes from other categories such as private-public partnerships and non-governmental organizations. The dataset can roughly be classified into small to medium-size firms (i.e., $41 \%$, no. of employees $<1000$ ) and large enterprises (i.e., $59 \%$, no. of employees $>1000$ ). The majority of responses come from high to executive managers, i.e., CEOs, CIOs, and IT management (approximately 70\%). Approximately $60 \%$ of the respondents had more than 11 years of working experience. Of all the respondents, $40 \%$ had even more than 20 years of experience.

As this research targets single respondents, there is a possibility that bias might exists. Hence, possible method bias was proactively accounted for to mitigate possible methods effects following guidelines by Podsakoff et al. [82]. Moreover, this study accounts for possible common method variance (CMV) per suggestions of Podsakoff [82]. T-tests group analyses for early (first two weeks) and later responses (final two weeks) for each research construct showed no significant differences, showing that possible non-response bias is not present. Finally, Harman's single factor test was performed using IBM SPSS Statistics ${ }^{\mathrm{TM}}$ v24 on the study constructs. Hence, the construct variables were all loaded on a single construct in an Exploratory Factor Analysis (EFA). Outcomes of this analysis showed that no single factor attributes to the majority of the variance; the sample is not affected by CMV [82].

\subsection{Constructs and Measurement Items}

This study attempted to include existing validated measures where possible.

EA deployment practices are a multidimensional construct that highlights the significance of using particular EA methods and deliberate deployment approaches to have projects comply with norms [49]. These practices also highlight the significance of EA principles for the strategic usage of the firm IS/IT and business resources across the enterprise [47,48]. Moreover, EA deployment practices foster firms to develop context-relevant enterprise architectural artifacts (e.g., models, business/IT mappings) across various architectural layers (e.g., business, information, and infrastructure layer) [50]. Hence, this study proposes these three measures (DP1-3) as a minimum baseline for EA deployment practices based on past empirical work and conceptual work.

This study newly conceptualizes the EA-based capability as a dynamic capability. Hence, this study adopts three elementary routines for dynamic capabilities, i.e.,: (1) EA-sensing capability (EAS), (2) EA-mobilizing capability (EAM), (3) EA-transforming capability (EAT) [20,22]. These underlying 
capabilities collectively form the dynamic enterprise architecture capabilities construct. A rigorous conceptual and theoretical development should precede the development of this construct. For this research, we employed an incremental approach in the development of this new multi-item scale following established guidelines [83]. First, measurement items were directed from either previously cited or implied by extant conceptual and empirical work $[4,23,24,27,74,77,84]$. The first pool of scale items was developed using a seven-point Likert-type scale, ranging from "strongly disagree" to "strongly agree". Two sub-phases of scale development and purification followed based on previously outlined recommendations [83], i.e., item-sorting analysis and expert reviews. The item-to-construct sorting approach was employed to establish tentative item reliability and validity [85], while expert reviews once more evaluated all the established scale items and offered improvement suggestions [86]. These two sub-phases enhanced the reliability and construct validity of dynamic enterprise architecture capabilities at a pre-testing stage. The results of these intensive phases are omitted for the sake of brevity. This second-order construct is modeled using the reflective-formative type II model $[87,88]$.

Business/IT-alignment (BA) is measured as a reflective first-order construct following [53,54], containing three existing items to capture the firms' IT strategic alignment between the business and IT plans, priorities, and strategies. Process innovation (PI) is likewise modeled as a reflective first-order construct following [52]. Relevant aspects include the extent to which firms have technological competitiveness and the novelty of technology used in critical processes.

This study follows Shanks et al. [4] for the multi-dimensional nature of organizational benefits. Hence, the current study considers organizational benefits to be the long-term firm benefits resulting from intermediate-capabilities and IT-business benefits. Organizational benefits are conceptualized as a second-order factor using the reflective-formative type II model and contains three underlying first-order benefits factors, i.e., process agility (PA) [55], competitive advantage (CA) [56,57], and increased value (VL) [58]. Process agility concerns the firms' "ability to detect and respond to opportunities and threats with ease, speed, and dexterity" [55]. This study used five validated items from Tallon and Pinsonneault [55]. Competitive advantage has several dimensions, including a higher return on investment than competitors, better market share growth than competitors, and better profitability. Finally, increased value is measured through customer satisfaction, customer loyalty, and business brand and image compared to competitors. This study controlled for possible confounding relationships by adding several widely-used control variables in IS research, i.e., firm size and age.

Table 2 shows all included measurement items, their respective item-to-construct loadings $(\lambda)$, mean values $(\mu)$, and the standard deviations (std.). Each item in the final survey was measured using a seven-point Likert scale (1: Strongly disagree to 7: Strongly agree).

\subsection{Model Estimations}

This study relied on the use of SmartPLS version 3.2.7. [89], which is a Structural Equation Modeling (SEM) application using Partial Least Squares (PLS) to estimate the research model and run parameter estimates. PLS-SEM is variance-based and is considered a better alternative than covariance-based modeling techniques (e.g., LISREL, AMOS) when the emphasis is on prediction, since PLS tries to maximize the explained variance in the dependent construct [90,91]. Additionally, PLS readily handles both reflective and formative measures [92,93], as is the case in this research, and PLS provides researchers with a greater ability to predict and understand the role and formation of latent constructs and their relationships among each other [90-92].

Analyses make use of the path weighing scheme within SmartPLS. Additionally, a non-parametric bootstrapping procedure was employed to compute the significance of the regression coefficients running from the first-order constructs to the second-order construct. In this process, 5000 replications were used to obtain stable results and to interpret their significance. Finally, the 299 organizations in the dataset far exceed all minimum requirements to run the SEM analyses $[93,94]$. 


\section{Empirical Validation}

\subsection{Evaluation of the Outer Model}

This study subjects the research model's constructs to internal consistency reliability, convergent validity, and discriminant validity test through SmartPLS [89]. At the construct level, a composite reliability (CR) assessment and the classic Cronbach's alpha measure (CA) was employed [90]. Typically, CA and CR values should be above 0.70 , as is the case in this research (see Table 3). Additionally, this study assessed construct-to-item loadings. None of the included items had to be removed, as all loadings were above 0.70 [95] (only one measurement item in the survey had a loading of 0.68 ; this is still in the range of acceptable item loadings). Next, this study assessed convergent and discriminant validity $[90,93]$. Hence, convergent validity was assessed by examining if the average variance extracted (AVE) is above the generally accepted lower limit of 0.50 [96]. All the obtained AVE values exceed the minimum threshold value. In a subsequent step, this study assessed the discriminant validity through three different but related tests. First, the data were assessed to detect high-loadings on the hypothesized constructs and low cross-loadings (i.e., correlations) on other constructs [97]. The data showed that all items load more strongly on their intended latent constructs than they correlate on other constructs. Second, the Fornell-Larcker criterion was assessed. In doing so, PLS was used to investigate if the square root of the AVEs of all constructs was larger than the cross-correlation (see the diagonal entries in bold in Table 3).

Table 3. Convergent and discriminant validity assessment of all the first-order reflective constructs.

\begin{tabular}{cccccccccc}
\hline & EADP & EAS & EAM & EAT & BA & PI & VL & CA & PA \\
\hline EADP ${ }^{1}$ & $\mathbf{0 . 8 9 2}$ & & & & & & & & \\
EAS & 0.668 & $\mathbf{0 . 8 2 8}$ & & & & & & & \\
EAM & 0.613 & 0.776 & $\mathbf{0 . 8 5 6}$ & & & & & & \\
EAT & 0.578 & 0.782 & 0.777 & $\mathbf{0 . 8 4 3}$ & & & & & \\
BA & 0.324 & 0.400 & 0.438 & 0.456 & $\mathbf{0 . 8 0 9}$ & & & & \\
PI & 0.209 & 0.258 & 0.245 & 0.409 & 0.413 & $\mathbf{0 . 8 7 2}$ & & & \\
VL & 0.216 & 0.215 & 0.280 & 0.223 & 0.374 & 0.330 & $\mathbf{0 . 8 7 5}$ & & \\
CA & 0.221 & 0.217 & 0.220 & 0.265 & 0.368 & 0.331 & 0.628 & $\mathbf{0 . 9 0 1}$ & \\
PA & 0.038 & 0.213 & 0.205 & 0.289 & 0.384 & 0.504 & 0.515 & 0.508 & $\mathbf{0 . 7 5 8}$ \\
AVE & 0.796 & 0.685 & 0.733 & 0.710 & 0.652 & 0.760 & 0.811 & 0.765 & 0.686 \\
CA & 0.872 & 0.885 & 0.909 & 0.918 & 0.738 & 0.895 & 0.883 & 0.897 & 0.812 \\
CR & 0.921 & 0.916 & 0.932 & 0.936 & 0.849 & 0.927 & 0.928 & 0.929 & 0.897 \\
\hline
\end{tabular}

\footnotetext{
${ }^{1}$ Note: EADP-EA deployment practices; EAS—EA sensing capability; EAM-EA mobilizing capability; EAT—EA transforming capability; BA-business-IT alignment; PI-process innovation; VL-value; CA-competitive advantage; PA—process agility.
}

All square root values are higher than the constructs' shared variances with other constructs in the model [93]. Finally, this study found additional evidence for discriminant validity by employing the relatively newly developed heterotrait-monotrait (HTMT) metric [98]. All values showed acceptable outcomes far below the conservative 0.90 upper bound. As shown in Table 3, the first-order reflective measures are valid and reliable. All first-order constructs demonstrate a significant relationship with their respective higher-order construct (i.e., dynamic enterprise architecture capabilities, and organizational benefits). Additionally, the assessed variance inflation factors (VIFs) are well below a conservative critical value of 3.5. In addition to the absence of non-significant relations between first-order capabilities and the second-order constructs, these outcomes indicate that no multicollinearity exists within our model [99].

\subsection{Evaluation of the Inner Model and Hypotheses Testing}

The literature proposes the Standardized Root Mean Square Residual (SRMR) as a new model fit index. It calculates the difference between observed correlations and the model's implied correlations 
matrix $[90,100]$. Hence, this study checks the model by assessing the model fit before further assessing the structural model and associated hypotheses. However, current model fit indices should be interpreted with caution, as these metrics are not fully established PLS-SEM evaluation criteria. The obtained 0.060 is below the conservative 0.08 mark that is proposed by [100]. As a final step, the model's predictive relevance is calculated using the $Q^{2}$ of our endogenous constructs (i.e., using Stone-Geisser's test). All $Q^{2}$ values are above the threshold value of zero, thereby indicating the overall model's predictive relevance. The structural model and the hypothesized relationships among the model's constructs can now be assessed.

The research models' fit, predictive relevance, and the structural model can now be evaluated.

The structural model explains $29 \%$ of the variance for organizational benefits $\left(R^{2}=0.29\right)$ after removing all non-significant relationships from the model. This outcome is considered a moderate effect [91]. Additionally, dynamic enterprise architecture capabilities explain $22.0 \%$ of the variance in business-IT alignment $\left(R^{2}=0.22\right)$ and $12 \%$ (i.e., $R^{2}=0.13$ ) of the variance in process innovation. Finally, EA deployment practices explain $45 \%$ of the variance in dynamic enterprise architecture capabilities $\left(R^{2}=0.45\right)$. Overall, these coefficients of determination support the research model's explanatory power, next to the model fit indices and the obtained significant path coefficients $(p<0.0001)$. Table 4 summarizes the structural model assessment findings and additionally shows the estimated effect sizes (with effect sizes, the specific contribution of particular exogenous constructs to an endogenous latent constructs $R^{2}$ can be determined) $\left(f^{2}\right)$ and the confidence intervals (Lower bound, $0.5 \%$-Upper bound, $99.5 \%)$ of the structural model analyses.

Table 4. Summary of the hypotheses testing and structural model outcomes.

\begin{tabular}{|c|c|c|c|c|c|c|}
\hline Model Path & Effect & $\begin{array}{l}\text { Effect Size } \\
\qquad\left(f^{2}\right)\end{array}$ & $\begin{array}{c}\text { Confidence } \\
\text { Interval } \\
\text { (Bias-Corrected) }\end{array}$ & $t$-Value & Sign. & Conclusion \\
\hline $\mathrm{EADP}^{1} \rightarrow$ DEAC & 0.668 & 0.804 & CI (0.555-0.749) & 17.96 & YES & $\begin{array}{c}\mathrm{H} 1 \\
\text { Supported }\end{array}$ \\
\hline $\mathrm{DEAC} \rightarrow \mathrm{BA}$ & 0.468 & 0.280 & CI (0.329-0.579) & 9.791 & YES & $\begin{array}{c}\mathrm{H} 2 \\
\text { Supported }\end{array}$ \\
\hline $\mathrm{BIA} \rightarrow \mathrm{OB}$ & 0.312 & 0.114 & CI (0.110-0.454) & 5.305 & YES & \\
\hline $\begin{array}{c}\mathrm{DEAC} \rightarrow \mathrm{BA} \rightarrow \mathrm{OB} \\
(\text { mediation by } B A)\end{array}$ & 0.146 & - & CI (0.068-0.229) & 4.688 & YES & $\begin{array}{c}\mathrm{H} 3 \\
\text { Supported }\end{array}$ \\
\hline $\mathrm{DEAC} \rightarrow \mathrm{PI}$ & 0.335 & 0.128 & CI (0.196-0.451) & 6.620 & YES & $\begin{array}{c}\mathrm{H} 4 \\
\text { Supported }\end{array}$ \\
\hline $\mathrm{PI} \rightarrow \mathrm{OB}$ & 0.332 & 0.130 & CI (0.185-0.467) & 5.848 & YES & \\
\hline $\begin{array}{l}\mathrm{DEAC} \rightarrow \mathrm{PI} \rightarrow \mathrm{OB} \\
\quad(\text { mediation by } P I)\end{array}$ & 0.111 & - & CI (0.054-0.187) & 4.284 & YES & $\begin{array}{c}\text { H5 } \\
\text { Supported }\end{array}$ \\
\hline \multicolumn{7}{|l|}{ Other assessed paths } \\
\hline $\mathrm{EADP} \rightarrow \mathrm{BA}$ & 0.017 & 0.0002 & CI (-0.179-0.207) & 0.231 & $\mathrm{NO}$ & $\begin{array}{l}\text { Mediation } \\
\text { by DEAC }\end{array}$ \\
\hline $\mathrm{EADP} \rightarrow \mathrm{PI}$ & -0.030 & 0.0006 & CI $(-0.224-0.170)$ & 0.399 & NO & $\begin{array}{l}\text { Mediation } \\
\text { by DEAC }\end{array}$ \\
\hline $\mathrm{DEAC} \rightarrow \mathrm{OB}$ & 0.063 & 0.004 & CI $(-0.074-0.2147)$ & 1.117 & NO & $\begin{array}{l}\text { No direct } \\
\text { effect }\end{array}$ \\
\hline Size $\rightarrow$ OB & 0.028 & 0.002 & CI $(-0.066-0.158)$ & 0.521 & NO & $\begin{array}{c}\text { No } \\
\text { confounding }\end{array}$ \\
\hline Age $\rightarrow$ OB & -0.065 & -0.005 & CI $(-0.184-0.039)$ & 1.207 & $\mathrm{NO}$ & $\begin{array}{c}\text { No } \\
\text { confounding }\end{array}$ \\
\hline
\end{tabular}

${ }^{1}$ Note: DEAC—dynamic enterprise architecture capabilities; OB—organizational benefits; BIA—business-IT alignment; PI-process innovation. 


\subsection{Mediation Analyses}

This study followed specific guidelines by $[90,101,102]$ for multiple mediation analysis procedures to address the imposed mediation effects within the research model specifically. First, dynamic enterprise architecture capabilities' direct effect on organizational benefits is both positive and significant $(\beta=0.31, t=5.398, p \leq 0.0001)$. Hence, this fulfills the first mediation condition, as suggested by Kenny [101].

Next, the significance of the indirect effects (i.e., mediating paths) was integrally established (i.e., simultaneous consideration of all mediating constructs) through a bootstrapping approach using a non-parametric resampling procedure [90,102]. Then, the included direct path (dynamic enterprise architecture capabilities (DEAC) $\rightarrow$ Organizational benefits $(\mathrm{OB})$ ) showed a non-significant relationship $(\beta=0.06, t=1.112, p=0.26)$. The specific indirect effects (DEAC $\rightarrow \mathrm{BA} \rightarrow \mathrm{OB}$ and DEAC $\rightarrow \mathrm{PI} \rightarrow \mathrm{OB}$, see Table 4) should be interpreted as the indirect effect of DEAC on OB through a given mediation construct (i.e., BA or PI) while controlling for the other mediating constructs. Additionally, we tested for the direct effect of EA deployment practices on BA and PI. The bootstrapping results were negative. This particular outcome implies that, indeed, dynamic enterprise architecture capabilities are the key enabler of BIA and PI, and that dynamic enterprise architecture capabilities fully mediated the effect of deployment practices.

This study concludes that full mediation characterizes this current structural model. Therefore, this study finds support for the five hypotheses, while all included control variables showed non-significant (n.s.) effects (see Table 4).

\section{Discussion and Conclusions}

\subsection{Theoretical Contributions}

Motivated by the call to provide empirical evidence on how EA-based capabilities drive business transformation and deliver benefits, this study shows how dynamic enterprise architecture capabilities benefit the firm using data from 299 Dutch-speaking firms. In doing so, this current study makes various substantial contributions to the IS literature. First, this study's outcomes extend the current knowledge on which organizational benefits can be achieved with EA resources, practices, and capabilities. Using our work and gleaned insights, scholars can now conduct more foundational analyses on EA's use and deployment in organizations. More specifically, they can now systematically link a firm's EA deployment practice efforts to dynamic capabilities and use them to efficiently exploit organizational resources and explain how the firm's innovativeness, alignment of business and IT, and organizational benefits can be achieved $[103,104]$. Second, with these outcomes, the present study also extends previous empirical studies that focus on project contributions from effective EA deployment, see, for instance, [4].

Third, this study constructed and validated a comprehensive EA-based capability and treated it as a dynamic capability. Using the 16 measurement items across three dimensions (i.e., EA sensing, mobilizing, and transforming capability), this study helps researchers conduct more systematic analyses on the organization's EA-based capabilities. Fourth, this study empirically showed that dynamic enterprise architecture capabilities, enabled by EA deployment practices, are crucial to achieving high business-IT alignment and process innovation levels. Furthermore, the latter two fully mediate the effect of dynamic enterprise architecture capabilities on organizational benefits. In doing so, this study expands upon previous EA-based capabilities and IT-enabled capabilities studies [2,4,57]. Specifically, the identified mechanisms, and thus the mediating forces, through which benefits are achieved have theoretical relevance since a substantial amount of scholarship work under the assumption that the sole development of EA's with associated artifacts is a sufficient condition to enable business transformation and attain organizational benefits $[6,10]$. This study shows that organizational benefits resulting from EA-based capabilities can be achieved through intermediate-capabilities and IT-business benefits. These current findings might explain why firms still encounter organizational and externally imposed 
obstacles with realizing EA's intended business outcomes [14,105]. The unfolded indirect effect of dynamic enterprise architecture capabilities on organizational benefits is also consistent with previous work on dynamic capabilities and their indirect effect on firm performance, see, for example, $[84,106]$. Our work could guide new areas of IS and EA research that focuses on dynamic enterprise architecture capabilities and their contribution to organizational value and firm innovativeness.

\subsection{Practical Contributions}

This study provides business and IT managers with a potent source of value. The literature paid considerable attention to EA artifacts and framework's key role as sufficient conditions to enable business and transformation and attain organizational benefits. However, this current work, building upon empirical evidence, emphasizes a broader dynamic capabilities perspective regarding EA practice deployment in firms. Firms should focus on dynamic enterprise architecture capabilities as an effective mechanism for promoting business-IT alignment and thus provide a better understanding of business processes and IS/IT, their interdependencies, and possible synergies. Dynamic enterprise architecture capabilities help cultivate the EA to reconfigure the business successfully and the IS/IT landscape, recombine resources, and to adjust for and respond to unexpected changes, and can thus be considered an essential driver for business-IT alignment. Another important managerial implication of this work is that firms can enable process innovation by deploying unique combinations of complementary resources and cooperation of cohesive units governed by dynamic enterprise architecture capabilities. Hence, dynamic enterprise architecture capabilities need to be positioned within the firm to enable both alignment and process innovation, thereby using EA-based capabilities to their full potential.

This study developed a comprehensive survey that on the item-level can be used as a diagnostic and (self)assessment tool, grounded in theory, so that managers can now open up the value-creating black box of EA and justify the investments made in the EA practice and 'EA as a strategy' [3]. We argue that decision-makers should embrace that EA investments cannot be cultivated instantly through direct performance benefits. Instead, this research unfolds the different and related value paths through which operational benefits and competitive firm performance gains can be achieved. Using dynamic enterprise architecture capabilities, business and IT managers can now leverage previously unavailable EA assets, resources, and sets of decision options. They can use them to enhance their firms' ability to change process innovativeness, orchestrate business processes with technologies, and enhance benefits and a competitive edge.

\subsection{Limitations and Future Work}

Several study limitations guide future work, despite the developed model's attractiveness and the assessments using reliable cross-sectional data. First, this study used self-reported data to test the hypothesized relationships in the research model. In doing so, it uses a similar approach as the studies of $[2,4,14,45]$, as objective measures are difficult to obtain. Although considerable time and effort were undertaken to account for possible measurement errors and bias, CMV may still be a concern, as both the dependent and focal explanatory variables are perceptual measures derived from the same respondent (i.e., single informant). Including multiple respondents from a single organization could further strengthen the inter-rater validity and improve the internal validity.

This study also did not triangulate the self-reported measures with, for example, potentially available archival data from public sources. Including these additional data (e.g., financial measures) could further validate the empirical outcomes' overall validity, as perceptual data are strongly correlated to objective measures $[4,63]$. This research encourages further research avenues. First, it would be valuable to look at the possible conditioning role of environmental turbulence, as previous studies have demonstrated its impact on organizational benefits $[55,57,74,107]$. Finally, this study concurs with Shanks et al. [4] in that longitudinal research could lead to an enhanced understanding of dynamic enterprise architecture capabilities and the process of obtaining organizational benefits. 
Author Contributions: Conceptualization, R.v.d.W.; Investigation, R.v.d.W.; Resources, S.K. (Sherah Kurnia); Supervision, R.v.d.W.; Visualization, R.v.d.W. and S.K. (Sherah Kurnia); Writing-original draft, R.v.d.W.; Writing-review \& editing, S.K. (Sherah Kurnia) and S.K. (Svyatoslav Kotusev). All authors have read and agreed to the published version of the manuscript.

Funding: This research received no external funding.

Acknowledgments: We would like to thank Tom Hendrickx, Kevin Billen, and Salo Langer for their contributions to the data collection and for sharing their perspectives in numerous discussions. Additionally, we are thankful for the active role of the respondents in making this study a success.

Conflicts of Interest: The authors declare no conflict of interest.

\section{References}

1. Weill, P.; Woerner, S.L. Is Your Company Ready for a Digital Future? MIT Sloan Manag. Rev. 2018, 59, 21-25.

2. Hazen, B.; Bradley, R.V.; Bell, J.E.; In, J.; Byrd, T.A. Enterprise architecture: A competence-based approach to achieving agility and firm performance. Management 2017, 193, 566-577. [CrossRef]

3. Ross, W.J.; Weill, P.; Robertson, D. Enterprise Architecture as Strategy: Creating a Foundation for Business Execution; Harvard Business Press: Boston, MA, USA, 2006.

4. Shanks, G.; Gloet, M.; Someh, I.A.; Frampton, K.; Tamm, T. Achieving benefits with enterprise architecture. J. Strateg. Inf. Syst. 2018, 27, 139-156. [CrossRef]

5. Tamm, T.; Seddon, P.B.; Shanks, G.; Reynolds, P. How does enterprise architecture add value to organisations. Commun. Assoc. Inf. Syst. 2011, 28, 141-168. [CrossRef]

6. Gong, Y.; Janssen, M. The value of and myths about enterprise architecture. Int. J. Inf. Manag. 2019, 46, 1-9. [CrossRef]

7. Kitsios, F.; Kamariotou, M. Business strategy modelling based on enterprise architecture: A state of the art review. Bus. Process Manag. J. 2019, 25, 606-624. [CrossRef]

8. Berg, M.V.D.; Slot, R.; Van Steenbergen, M.; Faasse, P.; Van Vliet, H. How enterprise architecture improves the quality of IT investment decisions. J. Syst. Softw. 2019, 152, 134-150. [CrossRef]

9. Lange, M.; Mendling, J.; Recker, J. An empirical analysis of the factors and measures of Enterprise Architecture Management success. Eur. J. Inf. Syst. 2016, 25, 411-431. [CrossRef]

10. Kotusev, S. Enterprise architecture and enterprise architecture artifacts: Questioning the old concept in light of new findings. J. Inf. Technol. 2019, 34, 102-128. [CrossRef]

11. Vessey, I.; Ward, K. The dynamics of sustainable IS alignment: The case for IS adaptivity. J. Assoc. Inf. Syst. 2013, 14, 283-311. [CrossRef]

12. Hinkelmann, K.; Gerber, A.J.; Karagiannis, D.; Thoenssen, B.; Van Der Merwe, A.; Woitsch, R. A new paradigm for the continuous alignment of business and IT: Combining enterprise architecture modelling and enterprise ontology. Comput. Ind. 2016, 79, 77-86. [CrossRef]

13. Pattij, M.; van de Wetering, R.; Kusters, R. From Enterprise Architecture Management to Organizational Agility: The Mediating Role of IT Capabilities. In Proceedings of the 32nd Bled eConference: Humanizing Technology for a Sustainable Society, Bled, Slovenia, 16-19 June 2019; University of Maribor Press: Maribor, Slovenia, 2019.

14. Brosius, M.; Aier, S.; Haki, K.; Winter, R. Enterprise Architecture Assimilation: An Institutional Perspective; Association for Information Systems: Atlanta, GA, USA, 2018.

15. Toppenberg, G.; Henningsson, S.; Shanks, G. How Cisco Systems used enterprise architecture capability to sustain acquisition-based growth. MIS Q. Exec. 2015, 14, 151-168.

16. Abraham, R.; Aier, S.; Winter, R. Two Speeds of EAM-A Dynamic Capabilities Perspective. In Trends in Enterprise Architecture Research and Practice-Driven Research on Enterprise Transformation; Springer: Berlin/Heidelberg, Germany, 2012; pp. 111-128.

17. Labusch, N.; Aier, S.; Winter, R. Beyond Enterprise Architecture Modeling-What are the Essentials to Support Enterprise Transformations? Enterp. Model. Inf. Syst. Archit. 2013, 13-26.

18. Van de Wetering, R. Dynamic Enterprise Architecture Capabilities and Organizational Benefits: An empirical mediation study. In Proceedings of the Twenty-Eigth European Conference on Information Systems (ECIS2020), Marrakech, Morocco, 15-17 June 2020. 
19. Pattij, M.; van de Wetering, R.; Kusters, R.J. Improving Agility Through Enterprise Architecture Management: The Mediating Role of Aligning Business and IT. In Proceedings of the AMCIS, Salt Lake City, UT, USA, 10-14 August 2020.

20. Van de Wetering, R. Dynamic Enterprise Architecture Capabilities: Conceptualization and Validation. In Business Information Systems; Springer: Seville, Spain; Cham, Switzerland, 2019.

21. Teece, D.J. Explicating dynamic capabilities: The nature and microfoundations of (sustainable) enterprise performance. Strateg. Manag. J. 2007, 28, 1319-1350. [CrossRef]

22. Van de Wetering, R. Enterprise Architecture Resources, Dynamic Capabilities, and their Pathways to Operational Value. In Proceedings of the Fortieth International Conference on Information Systems, Munich, Germany, 15-18 December 2019.

23. Overby, E.; Bharadwaj, A.; Sambamurthy, V. Enterprise agility and the enabling role of information technology. Eur. J. Inf. Syst. 2006, 15, 120-131. [CrossRef]

24. Sambamurthy, V.; Bharadwaj, A.; Grover, V. Shaping agility through digital options: Reconceptualizing the role of information technology in contemporary firms. MIS Q. 2003, 27, 237-263. [CrossRef]

25. Korhonen, J.J.; Molnar, W.A. Enterprise architecture as capability: Strategic application of competencies to govern enterprise transformation. In Proceedings of the 2014 IEEE 16th Conference on Business Informatics (CBI), Geneva, Switzerland, 14-17 July 2014; IEEE: Piscataway, NL, USA, 2014.

26. Gregor, S.; Hart, D.; Martin, N. Enterprise architectures: Enablers of business strategy and IS/IT alignment in government. Inf. Technol. People 2007, 20, 96-120. [CrossRef]

27. Drnevich, P.L.; Kriauciunas, A.P. Clarifying the conditions and limits of the contributions of ordinary and dynamic capabilities to relative firm performance. Strateg. Manag. J. 2011, 32, 254-279. [CrossRef]

28. Eisenhardt, K.M.; Martin, J.A. Dynamic capabilities: What are they? Strateg. Manag. J. 2000, 21, 1105-1121. [CrossRef]

29. Das, S.R.; Joshi, M.P. Process innovativeness and firm performance in technology service firms: The effect of external and internal contingencies. IEEE Trans. Eng. Manag. 2012, 59, 401-414. [CrossRef]

30. Barney, J. Firm resources and sustained competitive advantage. J. Manag. 1991, 17, 99-120. [CrossRef]

31. Wade, M.; Hulland, J. Review: The resource-based view and information systems research: Review, extension, and suggestions for future research. MIS Q. 2004, 28, 107-142. [CrossRef]

32. Bharadwaj, A.S. A resource-based perspective on information technology capability and firm performance: An empirical investigation. MIS Q. 2000, 24, 169-196. [CrossRef]

33. Makadok, R. Toward a synthesis of the resource-based and dynamic-capability views of rent creation. Strateg. Manag. J. 2001, 22, 387-401. [CrossRef]

34. Amit, R.; Schoemaker, P.J. Strategic assets and organizational rent. Strateg. Manag. J. 1993, 14, 33-46. [CrossRef]

35. Someh, I.A.; Frampton, K.; Davern, M.J.; Shanks, G.G. The Role of Synergy in using Enterprise Architecture for Business Transformation. In Proceedings of the ECIS 2016, İstanbul, Turkey, 12-16 June 2016.

36. Pavlou, P.A.; el Sawy, O.A. From IT leveraging competence to competitive advantage in turbulent environments: The case of new product development. Inf. Syst. Res. 2006, 17, 198-227. [CrossRef]

37. Van de Wetering, R.; Versendaal, J.; Walraven, P. Examining the relationship between a hospital's IT infrastructure capability and digital capabilities: A resource-based perspective. In Proceedings of the Twenty-fourth Americas Conference on Information Systems (AMCIS), New Orleans, LA, USA, 16-18 August 2018.

38. Kohli, R.; Grover, V. Business value of IT: An essay on expanding research directions to keep up with the times. J. Assoc. Inf. Syst. 2008, 9, 23. [CrossRef]

39. Kim, G.; Shin, B.; Kim, K.K.; Lee, H.G. IT capabilities, process-oriented dynamic capabilities, and firm financial performance. J. Assoc. Inf. Syst. 2011, 12, 487. [CrossRef]

40. Ahlemann, F.; Stettiner, E.; Messerschmidt, M.; Legner, C. Strategic Enterprise Architecture Management: Challenges, Best Practices, and Future Developments; Springer Science \& Business Media: Berlin/Heidelberg, Germany, 2012.

41. Winter, R.; Fischer, R. Essential layers, artifacts, and dependencies of enterprise architecture. In Proceedings of the 2006 10th IEEE International Enterprise Distributed Object Computing Conference Workshops, Hong Kong, China, 16-20 October 2006; IEEE: Piscataway, NL, USA, 2006. 
42. Teece, D.J.; Pisano, G.; Shuen, A. Dynamic capabilities and strategic management. Strateg. Manag. J. 1997, 18, 509-533. [CrossRef]

43. Schilke, O. On the contingent value of dynamic capabilities for competitive advantage: The nonlinear moderating effect of environmental dynamism. Strateg. Manag. J. 2014, 35, 179-203. [CrossRef]

44. Foorthuis, R.; Van Steenbergen, M.; Brinkkemper, S.; Bruls, W.A.G. A theory building study of enterprise architecture practices and benefits. Inf. Syst. Front. 2016, 18, 541-564. [CrossRef]

45. Schmidt, C.; Buxmann, P. Outcomes and success factors of enterprise IT architecture management: Empirical insight from the international financial services industry. Eur. J. Inf. Syst. 2011, 20, 168-185. [CrossRef]

46. Mikalef, P.; Pateli, A.; van de Wetering, R. IT architecture flexibility and IT governance decentralisation as drivers of IT-enabled dynamic capabilities and competitive performance: The moderating effect of the external environment. Eur. J. Inf. Syst. 2020, 29, 1-29. [CrossRef]

47. Lindstrom, A. On the syntax and semantics of architectural principles. In Proceedings of the 39th Annual Hawaii International Conference on System Sciences (HICSS’06), Kauai, HI, USA, 4-7 January 2006; IEEE: Piscataway, NL, USA, 2006.

48. Proper, E.; Greefhorst, D. The Roles of Principles in Enterprise Architecture; Springer: Berlin/Heidelberg, Germany, 2010.

49. Cameron, B.H.; McMillan, E. Analyzing the current trends in enterprise architecture frameworks. J. Enterp. Archit. 2013, 9, 60-71.

50. Schekkerman, J. How to Survive in the Jungle of Enterprise Architecture Frameworks: Creating or Choosing an Enterprise Architecture Framework; Trafford Publishing: Bloomington, IN, USA, 2004.

51. Davenport, T. Proces Innovation, Reengineering Work through Information Technology; Harvard Business School Press: Boston, MA, USA, 1993.

52. Prajogo, D.I.; Sohal, A.S. The relationship between TQM practices, quality performance, and innovation performance: An empirical examination. Int. J. Qual. Reliab. Manag. 2003, 20, 901-918. [CrossRef]

53. Bradley, R.V.; Pratt, R.M.E.; Byrd, T.A.; Outlay, C.N.; Wynn, D.E., Jr. Enterprise architecture, IT effectiveness and the mediating role of IT alignment in US hospitals. Inf. Syst. J. 2012, 22, 97-127. [CrossRef]

54. Chan, Y.E. Why haven't we mastered alignment? The importance of the informal organization structure. MIS Q. Exec. 2002, 1, 97-112.

55. Tallon, P.P.; Pinsonneault, A. Competing perspectives on the link between strategic information technology alignment and organizational agility: Insights from a mediation model. Mis Q. 2011, 35, 463-486. [CrossRef]

56. Chen, Y.; Wang, Y.; Nevo, S.; Jin, J.; Wang, L.; Chow, W.S. IT capability and organizational performance: The roles of business process agility and environmental factors. Eur. J. Inf. Syst. 2014, 23, 326-342. [CrossRef]

57. Rai, A.; Tang, X. Leveraging IT capabilities and competitive process capabilities for the management of interorganizational relationship portfolios. Inf. Syst. Res. 2010, 21, 516-542. [CrossRef]

58. Chen, J.-S.; Tsou, H.-T. Performance effects of IT capability, service process innovation, and the mediating role of customer service. J. Eng. Technol. Manag. 2012, 29, 71-94. [CrossRef]

59. Frampton, K.; Shanks, G.; Tamm, T.; Kurnia, S.; Milton, S. Enterprise Architecture Service Provision: Pathways to Value. In Proceedings of the ECIS 2015, Münster, Germany, 26-29 May 2015.

60. Aral, S.; Weill, P. IT assets, organizational capabilities, and firm performance: How resource allocations and organizational differences explain performance variation. Organ. Sci. 2007, 18, 763-780. [CrossRef]

61. Schryen, G. Revisiting IS business value research: What we already know, what we still need to know, and how we can get there. Eur. J. Inf. Syst. 2013, 22, 139-169. [CrossRef]

62. Henderson, J.C.; Venkatraman, N. Strategic alignment: Leveraging information technology for transforming organisations. IBM Syst. J. 1993, 32, 4-16. [CrossRef]

63. Wu, S.P.-J.; Straub, D.W.; Liang, T.-P. How information technology governance mechanisms and strategic alignment influence organizational performance: Insights from a matched survey of business and IT managers. MIS Q. 2015, 39, 497-518. [CrossRef]

64. Luftman, J.; Kempaiah, R. An update on business-IT alignment: “A line” has been drawn. MIS Q. Exec. 2007, $6,165-177$.

65. Kearns, G.S.; Lederer, A.L. A Resource-Based View of Strategic IT Alignment: How knowledge sharing creates competitive advantage. Decis. Sci. 2003, 34, 1-29. [CrossRef]

66. Chan, Y.; Reich, B. IT alignment: An annotated bibliography. J. Inf. Technol. 2007, 22, 316-396. [CrossRef] 
67. Wang, X.; Zhou, X.; Jiang, L. A method of business and IT alignment based on enterprise architecture. In Proceedings of the 2008 IEEE International Conference on Service Operations and Logistics, and Informatics IEEE/SOLI 2008, Beijing, China, 12-15 October 2008; IEEE: Piscataway, NL, USA, 2008.

68. Tallon, P.P. A process-oriented perspective on the alignment of information technology and business strategy. J. Manag. Inf. Syst. 2007, 24, 227-268. [CrossRef]

69. Breznik, L.; Hisrich, R.D. Dynamic capabilities vs. innovation capability: Are they related? J. Small Bus. Enterp. Dev. 2014, 21, 368-384. [CrossRef]

70. Niemi, E.; Pekkola, S. Using enterprise architecture artefacts in an organisation. Enterp. Inf. Syst. 2017, 11, 313-338. [CrossRef]

71. Giniuniene, J.; Jurksiene, L. Dynamic capabilities, innovation and organizational learning: Interrelations and impact on firm performance. Procedia Soc. Behav. Sci. 2015, 213, 985-991. [CrossRef]

72. Assink, M. Inhibitors of disruptive innovation capability: A conceptual model. Eur. J. Innov. Manag. 2006, 9, 215-233. [CrossRef]

73. Teece, D.; Peteraf, M.; Leih, S. Dynamic capabilities and organizational agility: Risk, uncertainty, and strategy in the innovation economy. Calif. Manag. Rev. 2016, 58, 13-35. [CrossRef]

74. Pavlou, P.A.; el Sawy, O.A. Understanding the elusive black box of dynamic capabilities. Decis. Sci. 2011, 42, 239-273. [CrossRef]

75. Lapalme, J. Three schools of thought on enterprise architecture. IT Prof. 2012, 14, 37-43. [CrossRef]

76. Yu, E.; Deng, S.; Sasmal, D. Enterprise architecture for the adaptive enterprise-A vision paper. In Trends in Enterprise Architecture Research and Practice-Driven Research on Enterprise Transformation; Springer: Berlin/Heidelberg, Germany, 2012; pp. 146-161.

77. Mikalef, P.; Pateli, A.; van de Wetering, R. IT flexibility and competitive performance: The mediating role of IT-enabled dynamic capabilities. In Proceedings of the 24th European Conference on Information Systems (ECIS) 2016, Istanbul, Turkey, 12-15 June 2016.

78. Roberts, N.; Galluch, P.S.; Dinger, M.; Grover, V. Absorptive Capacity and Information Systems Research: Review, Synthesis, and Directions for Future Research. MIS Q. 2012, 36, 625-648. [CrossRef]

79. Hult, G.T.M.; Hurley, R.F.; Knight, G.A. Innovativeness: Its antecedents and impact on business performance. Ind. Mark. Manag. 2004, 33, 429-438. [CrossRef]

80. Gray, B.J.; Matear, S.; Matheson, P.K. Improving service firm performance. J. Serv. Mark. 2002, 16, 186-200. [CrossRef]

81. Ministry of Economic Affairs and Climate Policy. Dutch Digitisation Strategy 2.0. It's Possible Here. It's Happening Here; Ministry of Economic Affairs and Climate Policy: The Hague, The Netherlands, 2019.

82. Podsakoff, P.M.; MacKenzie, S.B.; Lee, J.Y.; Podsakoff, N.P. Common method biases in behavioral research: A critical review of the literature and recommended remedies. J. Appl. Psychol. 2003, 88, 879. [CrossRef]

83. MacKenzie, S.B.; Podsakoff, P.M.; Podsakoff, N.P. Construct measurement and validation procedures in MIS and behavioral research: Integrating new and existing techniques. MIS Q. 2011, 35, 293-334. [CrossRef]

84. Wilden, R.; Gudergan, S.P.; Nielsen, B.B.; Lings, I. Dynamic capabilities and performance: Strategy, structure and environment. Long Range Plan. 2013, 46, 72-96. [CrossRef]

85. Moore, G.C.; Benbasat, I. Development of an instrument to measure the perceptions of adopting an information technology innovation. Inf. Syst. Res. 1991, 2, 192-222. [CrossRef]

86. Presser, S.; Couper, M.P.; Lessler, J.T.; Martin, E.; Martin, J.; Rothgeb, J.M.; Singer, E. Methods for testing and evaluating survey questions. Public Opin. Q. 2004, 68, 109-130. [CrossRef]

87. Becker, J.-M.; Klein, K.; Wetzels, M. Hierarchical latent variable models in PLS-SEM: Guidelines for using reflective-formative type models. Long Range Plan. 2012, 45, 359-394. [CrossRef]

88. Jarvis, C.; MacKenzie, S.; Podsakoff, P. A critical review of construct indicators and measurement model misspecification in marketing and consumer research. J. Consum. Res. 2003, 30, 199-218. [CrossRef]

89. Ringle, C.M.; Wende, S.; Becker, J.-M. SmartPLS 3. Boenningstedt: SmartPLS GmbH. 2015. Available online: http://www.smartpls.com (accessed on 4 September 2020).

90. Hair Jr, J.F.; Hult, G.T.M.; Ringle, C.; Sarstedt, M. A Primer on Partial Least Squares Structural Equation Modeling (PLS-SEM); Sage Publications: Thousand Oaks, CA, USA, 2016.

91. Chin, W. The partial least squares approach to structural equation modeling. In Modern Methods for Business Research; Marcoulides, G.A., Ed.; Lawrence Erlbaum Associates: Mahwah, NJ, USA, 1998; pp. 295-336. 
92. Ringle, C.M.; Sarstedt, M.; Straub, D.W. 'Editor's Comments: A Critical Look at the Use of PLS-SEM in “MIS Quarterly". MIS Q. 2012, 36, iii-xiv. [CrossRef]

93. Hair, J.F., Jr.; Sarstedt, M.; Ringle, C.M.; Gudergan, S.P. Advanced Issues in Partial Least Squares Structural Equation Modeling; Sage Publications: Thousand Oaks, CA, USA, 2017.

94. Hair, J.F.; Ringle, C.M.; Sarstedt, M. PLS-SEM: Indeed a silver bullet. J. Mark. Theory Pract. 2011, 19, $139-152$. [CrossRef]

95. Fornell, C.; Bookstein, F. Two structural equation models: LISREL and PLS applied to consumer exit-voice theory. J. Mark. Res. 1982, 19, 440-452. [CrossRef]

96. Fornell, C.; Larcker, D. Evaluating structural equation models with unobservable variables and measurement error. J. Mark. Res. 1981, 18, 39-50. [CrossRef]

97. Farrell, A.M. Insufficient discriminant validity: A comment on Bove, Pervan, Beatty, and Shiu (2009). J. Bus. Res. 2010, 63, 324-327. [CrossRef]

98. Henseler, J.; Ringle, C.M.; Sarstedt, M. A new criterion for assessing discriminant validity in variance-based structural equation modeling. J. Acad. Mark. Sci. 2015, 43, 115-135. [CrossRef]

99. Kock, N.; Lynn, G. Lateral collinearity and misleading results in variance-based SEM: An illustration and recommendations. J. Assoc. Inf. Syst. 2012, 13, 1-40. [CrossRef]

100. Hu, L.t.; Bentler, P.M. Cutoff criteria for fit indexes in covariance structure analysis: Conventional criteria versus new alternatives. Struct. Equ. Model. Multidiscip. J. 1999, 6, 1-55. [CrossRef]

101. Baron, R.M.; Kenny, D.A. The moderator-mediator variable distinction in social psychological research: Conceptual, strategic, and statistical considerations. J. Personal. Soc. Psychol. 1986, 51, 1173. [CrossRef]

102. Hayes, A.F. Introduction to Mediation, Moderation, and Conditional Process Analysis: A Regression-Based Approach; Guilford Press: New York, NY, USA, 2013.

103. Danneels, E. The dynamics of product innovation and firm competences. Strateg. Manag. J. 2002, 23, 1095-1121. [CrossRef]

104. Wilden, R.; Gudergan, S.P. The impact of dynamic capabilities on operational marketing and technological capabilities: Investigating the role of environmental turbulence. J. Acad. Mark. Sci. 2015, 43, 181-199. [CrossRef]

105. Löhe, J.; Legner, C. Overcoming implementation challenges in enterprise architecture management: A design theory for architecture-driven IT Management (ADRIMA). Inf. Syst. e-Bus. Manag. 2014, 12, 101-137. [CrossRef]

106. Protogerou, A.; Caloghirou, Y.; Lioukas, S. Dynamic capabilities and their indirect impact on firm performance. Ind. Corp. Chang. 2012, 21, 615-647. [CrossRef]

107. Fainshmidt, S.; Wenger, L.; Pezeshkan, A.; Mallon, M.R. When do dynamic capabilities lead to competitive advantage? The importance of strategic fit. J. Manag. Stud. 2019, 56, 758-787. [CrossRef]

Publisher's Note: MDPI stays neutral with regard to jurisdictional claims in published maps and institutional affiliations.

(C) 2020 by the authors. Licensee MDPI, Basel, Switzerland. This article is an open access article distributed under the terms and conditions of the Creative Commons Attribution (CC BY) license (http://creativecommons.org/licenses/by/4.0/). 